\title{
Žene, Jugoslavija, antikomunistička narkoza i novi kolonijalizam: mape, putevi, izlazi
}

\begin{abstract}
Slapšak Svetlana, Žene, Jugoslavija, antikomunistička narkoza i novi kolonijalizam: mape, putevi, izlazi (Women, Yugoslavia, Anti-communist Anesthesia, Neocolonialism: Maps, Ways, Exits). „Poznańskie Studia Slawistyczne” 5. Poznań 2013. Adam Mickiewicz University Press, pp. 249-263. ISBN 978-83-232-2636-9. ISSN 2084-3011.

In the paper the author tries to map out critically the situation within gender studies and their academic production in the region: the uncomfortable dealing with „Yugoslavia”, the overall situation of humanities and social sciences, the political, social and cultural backlash of women's position/rights and visibility in the whole post-socialist world, the consequences of the war, the Western feminists', academics, media and intellectuals' impact on the interpretation of the war, of which all can be connected with the provoking terms in the title. The author illustrates the situation with some of the examples of the Western academic and cultural dealing with the war and local feminism, and some problems of situating the „Yugoslav nostalgia”. The author proposes several theoretical and methodological approaches which could enable gender studies and humanities' academics in the region to grasp the problems from the new perspective: work/research au pair, the concept of twin cultures, the method of ground-truthing.
\end{abstract}

Keywords: gender; Yugoslavia; nostalgic; new colonialism; au pair; twin cultures; groundtruthing

Prizivati u sećanje akademsku produkciju u regionu u poslednjih dvadesetak godina, obeleženih raspadom Jugoslavije i ratom, nije posebno zahvalna radnja: ako se sumira šta je sve objavljeno na engleskom jeziku, prihvaćeno u međunarodnoj akademskoj sredini, citirano i potvrđeno kao važna faza u zabeležavanju istorije, sećanja, teorije i metodologije nauke o rodu, može se samo žaliti za propuštenim prilikama. Pod pretpostavkom da bi upravo lokalno znanje moralo biti od ključnoga značaja, postaviću hipotezu koja proizlazi iz dvadeset godina praćenja akademske produkcije 
- da nema mnogo povoda za divljenje ni u dostignućima na planu međunarodne akademske saradnje, ni u međunarodnoj promociji lokalnih akademskih dostignuća. Možda to izgleda kao stroga ili čak nepravedna ocena i mnoge/mnogi će pomisliti da bi to mogli porušiti bibiliografijom koju bi mogli improvizovati samo iz sećanja. Tu ja pre svega mislim na „senku” koja se nadvila nad lokalnu akademsku produkciju, na kolonijalno ponašanje koje je imalo izrazitiji, da ne kažem agresivniji oblik u prvoj od dve decenije koje su ovde u pitanju. Reč je o postupcima grabljenja, banaliziranja ,vrućih" tema (kao što je izvesno bilo silovanje žena u Bosni i Hercegovini), tretiranja takvih tema sa besramnim neznanjem, nezanimanjem za lokalne izvore i ponekad s arbitrarnim, plitkim i nepouzdanim izborom lokalnih činjenica i informacija. Da bi stvari bile gore, ovakvoj su kolonijalnoj situaciji pomagali domaći, spremni da dokažu svoju poziciju kolonizovanog. To je veoma ozbiljan problem u regionu, jer je „mudrost kolonizovanog” ubitačna u učvršćivanju konzervativnih „vrednosti”, koje su nametnute kao model oslobođenja od socijalističkih ideoloških ograničavanja i istovremeno uvođenja nacionalističkih diskursa i praksi umesto njih. „Mudrost kolonizovanog” po pravilu upućuje na ćutanje i druge antropološke znake nove distribucije moći kroz nove kanale. Međunarodna akademija, često usmerena prema medijskom odobravanju i zarađivanju, odnosno pribavljanju sredstava, više je nego zadovoljna sa jednim, ređe dva ili više predstavnica/predstavnika male i egzotične kulture, i ostaje slepa za bilo šta drugo (više) iz istog geo-kulturnog prostora. Primera radi, globalna saturacija medijskom prisutnošću Slavoja Žižeka je uvek povezana sa konotacijom „Slovenija”: nedvosmisleno, to je jedan od važnih ,prodajućih", tržnih elemenata u paketu ove skoro svakodnevne produkcije banalnosti.

Kako se moglo dogoditi da su, sa druge strane, mreže solidarnosti, stvorene za vreme rata, mogle toliko oslabiti, uglavnom zbog želje za moći i karijerom? Kako je moguće da su regionalne ženske mreže proizvele toliko relevantnih tekstova koji nisu uzimani u obzir od strane akademskih centara moći? Ti tekstovi su po pravilu retko citirani, još ređe ugrađeni u nastavne procese, skoro nikada prevođeni. Već godinama (bar od 1994), književni i žurnalistički tekstovi iz regiona se jedini pojavljuju u propisanim bibliografijama na univerzitetskim kursevima u SAD, kao da u regionu nikada nije postojala akademska produkcija. A kada su teme prestale 
biti „vruće”, zanimanje se takođe izgubilo, i sa njim mogućnost da se ponovno otvore neka pitanja i promisle neke istorijske procene. Proces je imao mnogostrane učinke i posledice: lokalna akademska populacija, posebno u rodnim studijama, izgubila je, gotovo istovremeno, finansijsku pomoć u domaćem i međunarodnom akademskom svetu. Bez potvrđene pomoći, postalo je mnogo teže osvojiti mesto na domaćem terenu, dobro natopljenim konzervativnim i nacionalističkim diskursima tokom prošlih godina. Prethodne disidentske mreže i aktivizam u nekadašnjem socijalističkom sistemu su ostali u prošlosti. Postalo je neophodno ponovo osposobiti veze između Centralne, Istočne i Južne Evrope. Možda najžalosnije od svega toga, lokalna neuroza među feministikinjama se počela iskazivati u niskim emocijama oko zasluga, odgovarajućih hijerarhija i zauzimanja mesta u kanonskim establišmentskim konstruktima.

Jedna od glavnih posledica je izvesno to da je objavljivanje na engleskom postalo neizbežno, no sa druge strane, prevođenje sa engleskog svega i svačega više nije sasvim nužno. A i moguće nove strategije bi mogle izaći iz ove naizgled tužne situacije: lokalne studije roda moraju istražiti, oceniti i promovisati sopstvenu istoriju, koja je inače iz različitih razloga minimalizovana i od strane lokalne i od strane akademije izvan lokalnog akademskog prostora. Te studije se moraju razvijati, debatovati, reflektirati i zahtevati nove teorijske pristupe. Moje lično iskustvo sa ovim upravo iznesenim programom bila je prava katastrofa. Dala sam predlog za zbornik o metodologiji balkanskih ženskih studija u seriji zbornika sa ,učenjem" u naslovu, i studiju za taj zbornik. To se dešavalo 2010. g. Oba, članak i zbornik, bili su deo projekta u okviru mreže ATHENA 1-3, izuzetno uspešnog evropskog programa rodnih studija, posebno dok ga je vodila Rosi Braidotti. Ona je naime imala izuzetno osećanje i energiju da pomogne studijama roda u Centralnoj, Istočnoj i Južnoj Evropi. Bila je dobro obaveštena o razvoju i događanjima o feminističkoj teoriji i aktivizmu, jer je sarađivala na međunarodnim kongresima o ženskom pismu u Dubrovniku 1986-1990, koje su organizovale jugoslovenske feminstkinje. I moj već pripremljeni zbornik i članak su odbijeni. Moje nekadašnje koleginice su argumentovale odbacivanje time što moj članak nije privlačio moguće studente, jer je zahtevao suviše specifičnih znanja i veština (na primer poznavanje engleskog jezika). 
Nova organizacija studija roda posle mreže ATHENA 1-3, zasnovana na novcu od članarina, ima drugačiju agendu ${ }^{1}$. Na simboličkom nivou to me je iskustvo načinilo mnogo osetljivijom i obazrivijom u posmatranju onoga što se događa u regionu: tome se još mora dodati više refleksije o našem novom pozicioniranju. Više kritike i samokritike je postalo neophodno u svakom istraživanju koje smo ponovo započinjale, proveravale ili otvarale. Moje ponovno pozicioniranje je uzelo pravac koji mapiram ovim prilogom. Na ličnom nivou, to je značilo novi trening u uništavanju samosažaljenja, osećanja izolovanosti, više kritičnosti prema sentimentalnosti koja se „lepi” na male kolektive i konačno prihvatanje da je ono što ja radim i ono što mi radimo još uvek duboko zavisno od engleske verzije rada u pitanju.

Cilj ove intervencije bi se mogao odrediti kao pokušaj da se mapira metodološki i konceptualno konfuzno područje koje obuhvata kulture unutar prostora koji povezuje nove države, nekada republike jugoslovenske federacije, a posebno sve što se tiče položaja žena i feminizma. Sa formalnim krajem jugoslovenskih ratova 1995, akademska produkcija u regiji, koja je uspešno preživljavala tokom ratnih konflikata, zahvaljujući očitom interesu međunarodne zajednice, izrazito je opala. Novi impuls dalo je proučavanje posleratne popularne kulture. Izvesno je da u tome području nema nekog „tematskog rizika”, ali je izazov upravo u tome kako se obratiti problemu, kako izbeći kontaminaciju diskurzivnih strategija koje vladaju u tome polju i manipuliraju odgovornošću, menjanjući sećanje na prošli rat i zamagljujući s tim ustanovljene minimalne etičke polaritete. Dekodiranje može biti teško izvan domaćeg konteksta, može se zaći u dodatno stereotipiziranje, a zamke igre prihvatljivosti između lokalnih okolnosti i međunarodne akademije mogu biti surove, vrlo slično onima koje sam nedavno primetila u području studija roda (i gore opisala).

Država Jugoslavija je istorijska činjenica, trajala je od 1919. do 1991. Etikete tipa eks- ili post- su samo svedočanstva političkog investiranja ili skrivenih tabua koji proizlaze iz ,servisnih” naracija u državama koje su nastale iz jugoslovenskih republika. Nužno je dakle neutralizovati ime,

\footnotetext{
${ }^{1}$ The AtGender network.
} 
kako bi se izbegle sve moguće manipulacije. „Bivša Jugoslavija” je nepotrebna tautologija, koja nosi slične konotacije i povećava konfuziju, sa tri države koje su nosile ime Jugoslavije (monarhija, socijalistička federacija, para-federacija pod Srbijom za vreme rata). Jednostavno ime-termin Jugoslavija izbegava moguće spekulacije i tabue: termin naime, uz dodatke, obično označava pozicioniranje u javnom diskursu. Neki se odlučuju za epitet „komunistička Jugoslavija”, neki osećaju potrebu da se izvinu dok ga koriste. Neutralizacija ima smisla kao proizvod nulte pozicije, kako bi se stvorila zajednička semantička početna tačka. Drugi slučaj zastranjivanja je nekritička upotreba termina Zapadni Balkan, koju odlikuje istorijska i geografska arbitrarnost i koja je znak pre svega političke agende međunarodne zajednice i delova lokalnih političkih elita. Razlog za to vidim u generalnom nedostatku fiksiranog akademskog žargona, koji bi morao biti prikazan u redovnoj akademskoj produkciji, periodici i knjigama. Terminološku disciplinu je teško očuvati, ako lokalnu akademsku populaciju strogo kontrolišu i lokalno nacionalno/nacionalističko uslovljavanje, i nametnute mode koje dolaze uglavnom iz anglo-američkih akademskih izvora. U takvoj situaciji se može lako dogoditi da profesionalni trikovi zamene ozbiljnu brigu oko terminološke tačnosti. Dobar primer ovakve zapletene mreže strategija sa mnogo nivoa i autentičnih pokušaja da se reše neki konceptualni problemi je termin titostalgija, koji Mitja Velikonja uvodi u svojoj istoimenoj knjizi (Velikonja 2010). O ovome primeru neću posebno opširno govoriti ${ }^{2}$, ali bih volela da navedem nekoliko drugih primera koji nose očite znakove kolonijalnih strategija i obeleženi su brzinom, željom za moći i negacijom akademskog doprinosa iz regiona koji akademski eksploatišu.

1. Alexandra Stiglmayer, urednica zbornika koji je pripremljen posle otkrića Roya Gutmana o masovnim silovanjima u Bosni i Hercegovini, dozvolila je poveliki broj materijalnih i drugih netačnosti, koji nose tipični pečat kolonijalne žurbe (Stiglmayer (ur.) 1994) - netačno napisana imena, neznanje istorijskih činjenica, neproverene infromacije.

2. Bar tri evropska intelektualca, Bernard-Henry Levy, Alain Finkielkraut i Peter Handke su ponovo odigrali ulogu „sveca malog naroda” za vreme rata u Jugoslaviji. Prvobitno je ulogu osmislio i odigrao lord Byron

\footnotetext{
${ }^{2}$ Detaljnija rasprava o tome objavljena je u Slapšak 2011.
} 
za vreme rata za oslobađanje Grčke. Narativni model je i danas, dva veka kasnije, očito privlačan za intelektulace koji bi velikim događajima rado pridružili svoja imena. Tako je za vreme rata Levy odabrao Bosnu i Hercegovinu, Finkielkraut Hrvatsku, a Handke Srbiju. Levy je uhvaćen kako za kameru izvodi ,herojsku” scenu u ratom uništavanom Sarajevu ${ }^{3}$, Finkielkraut je nazvao Tuđmana velikim književnim stvaraocem, denuncirao književnicu Dubravku Ugrešić kao predstavnicu komunističke nomenklature, i objavio knjigu (1992) o tome kako biti Hrvat, bez bilo kakvog znanja jezika (Finkielkraut 1992). Handke je objavio knjigu u kojoj se Srbi prikazuju kao najveće žrtve rata i negira se genocid u Bosni i Hercegovini (Handke 1996b).

3. U svojoj knjizi o jugoslovenskom ratu 1994, Renta Salecl je negirala postojanje jugoslovenskog feminizma i time sebe proglasila za jedinu feministkinju koja dolazi iz nekadašnje Jugoslavije. Tumačila je da su silovatelji u Bosni i Hercegovini „lišili” muslimanske žene njihovog užitka:

The sad fact is that no serious feminist movement exists in post-socialist countries. There are few feminist groups with any public impact. There are several reasons for this lack of feminism. First, no feminist tradition existed under socialism. Second, as is well known, socialism was a very patriarchal society, in spite of the official claim that it solved the woman question. Furthermore, feminism did not emerge after the fall of socialism because women perceive it as being unfeminine (Salecl 1994: 4).

Već 1993 je Nanette Funk otvorila ključno pitanje o američkim istraživačicama u istočnoj Evropi, koje su pohrlile u regiju i nametnule joj feminističku teoriju bez poštovanja akademskih dostignuća i čak realnosti položaja tamošnjih žena i njihovih zakonskih prava u socijalističkim zemljama (Funk, Mueller (ur.) 1993). Time su istraživačice sebe smestile u istu grupu sa lokalnim mizoginim glasovima, koji su tvrdili da su žene zapravo odgovorne za komunizam, jer im je dao nova prava. Sa druge strane je pristup istraživanju post-socijalističkih žena bio često finansiran i olakšan uz pomoć institucija, potpore i sredstava koja su izvor imala u starim antikomunističkim stavovima i idejama. Proces su ključno pomogli lokalni istraživači/istraživačice, koji su bili spremni da falsifikuju prethodni realni

\footnotetext{
${ }^{3}$ Epizodu je razotkrio i ismejao satirički francuski časopis „Canard Enchainé”.
} 
položaj žena da bi pridobili nove položaje i moć - na račun svih žena. To je bilo naročito podmuklo obavljeno na primeru Jugoslavije, gde je feministički pokret bio na samome vrhu teoretske refleksije u Evropi pred rat 1991, i kasnije, za vreme rata, vodeća sila u antiratnim akcijama i mrežama solidarnosti.

Pozicija feminističkih misliteljki i njihov stav prema pitanjima feminizma, roda i žena ili određena ne-pozicija ${ }^{4}$ koja je jugoslovenske feministkinje dovela do organizovanja sopstvenog prostora dijaloga $\mathrm{i}$ istraživanja za sebe, bila je omeđena strategijama oko feminizma u zaklonu-kraljevstvu disidentske misli i produkcije: ženska prava je odredila i održavala vladajuća komunistička ideologija, bila su garantovana ustavom i pravnim regulativama države, dakle nije bilo potrebe otvarati nekakva feministička pitanja. Problemi feminizma, žena i roda nisu bili prioritetni u procesu menjanja ideoloških okvira društva i političkog pejzaža, mogli su čekati bolji trenutak. Konačno, pitanja vezana za feminizam, žene i rod nisu bila dovoljno „ozbiljna” da bi se njima bavili disidentska akademija i disidentski mislioci. Premda uvredljivo banalan, ovaj patrijarhalni mentalitet je prevladavao u disidentskim krugovima, sa retkim izuzecima. Sama sam imala ozbiljan problem distanciranja od visokih ciljeva promene društvenih odnosa i od samih disidentskih krugova, koji su bili moja kulturna i socijalna zona od 1968, da ,transgrediram” u feminizam, koji na početku nije mahao zastavom tako ambiciozne političke agende. Do kraja 80-ih se velika većina disidentske populacije opredelila za nacionalističke programe, separatizam i posledično rat, dok su feministički krugovi davali prednost miru po svaku cenu i kontinuitetu države Jugoslavije, koja je jedina mogla garantovati funkcionalno rešenje za mirno prestrukturiranje. Rat u Jugoslaviji je imao neobičan preokret, postavši istovremeno i rat rodova: već od 80-ih nesputana mizoginija je karakterisala medije u Jugoslaviji, ali i kulturnu produkciju i prevlađujuće naracije. To je od strane režima bilo tolerisano, jer je od sredine 60-ih partijska vlast uvodila nekakvo kontrolisano potrošačko društvo, koje je uključivalo i masovnu pornografsku produkciju

\footnotetext{
${ }^{4}$ Važno je reći da nijedan pokušaj približavanja stavova ili akcija jugoslovenske disidencije posle 1968. i feminizma nije uspeo, uglavnom zbog odbijanja od strane disidenata. Jedini, koji je dosledno pratio feminizam, objavio značajnu osnovnu bibliografiju (do 1980) i pokazivao razumevanje je Nebojša Popov, izbačen sa Filozofskog fakulteta i docnije glavni urednik časopisa „Republika” u Beogradu.
} 
- štampanu, filmsku i televizijsku. Na drugoj strani mizoginija je bila strukturno ugrađena u glavnu naraciju takozvanog crnog filmskog talasa, sa ženom kao zlobnim reprezentantom komunističkog režima. Samo uz poznavanje takvih detaljnih okolnosti konteksta mogu se objasniti specifične kulturne, medijske i socijalne situacije, tako da argument o društvenoj i kulturnoj pozadini ostane pouzdan. To bi moglo poslužiti kao osnovni okvir mapiranja disciplinarnog područja u kojem je obilje istraživačkih tema i u kojem se istraživanje pokazuje kao zahvalno i plodno. Da li ono generira posebnu etičku brižnost i refleksiju?

Možda će moj argument o lokalnom/domaćem izgledati previše trivijalan. Prvi problem koji vidim je svakako izbor jezika, s tim da je jasno nužno objavljivati na engleskom. Drugi je posledica toga - lingvistički kolonijalizam koji zapravo nema alternative. Nije dakle sasvim jasno imamo li mi ovde posla sa fenomenom kolonijalizma ili sa načinom emancipacije. I to je ozblijna dilema za istraživača. Na strani međunarodne populacije istraživača, opšti i tihi komoditet nepoznavanja lokalnog jezika, čak i u slučaju kada je akademska ambicija istraživača usmerena na „seksi” temu koja zahteva poznavanje jezika - izvesno pripada kolonijalnom ponašanju. Moj predlog je da se izmisle i uvedu novi tipovi au pair saradnje među istraživačima, što ne bi smeo biti problem među istraživačicama, odnosno u populaciji studija roda. Zamislimo, recimo, instituciju iz 19. veka, au pair, što bi danas značilo ponuditi gostoprimstvo istraživačici ne samo u onim oblicima za koje danas postoje različite institucionalne mogućnosti, već u smislu saradnje dve ili više istraživačica na jednoj temi i sa jednakim autorstvom. Jedna istraživačica, na primer, obezbeđuje lingvističku kompetenciju druga/druge brinu za dostup evropskim fondovima. Mladi istraživači su danas svesni da se fondovi smanjuju za mlade istraživače, da je porast privilegija velikih zemalja i univerziteta unutar EU zastrašujući, da je stabilna zaposlenost na duže vreme u akademiji i istraživačkim ustanovama prava retkost, da akademske publikacije po pravilu nisu honorisane: ogromna količina energije i vremena mora se utrošiti na pisanje potpuno irelevantnih birokratskih tekstova da bi u takvim okolnostima preživele. Previše često takav razvoj stvari nije u vezi sa kriterijumima istraživanja niti važećim standardima kvaliteta istraživanja. U spirali loših rešenja i ideja, humanistika i društvene nauke kližu nadole na lestvici imaginarnih intelektualnih kvaliteta EU, i što je još opasnije, takav menta- 
litet deluje na procese odlučivanja i na javni diskurs. Izabrati jednu od najmanje privilegovanih niša na takvoj mapi disciplina i akademskih prioriteta, koje nisu ni konačno konfigurirane, predstavlja visoki rizik pri pojedinačnom odlučivanju. Mislim da je saradnja u regionu moguća. Nedavno je izvrstan primer potvrdio da je ideja primenljiva: Chiara Bonfiglioli je odbranila doktorsku tezu, a zatim pridobila cum laude status za nju na utrehtskom univerzitetu (Bonfiglioli 2012). Da bi istraživala, naučila je srpsko-hrvatsko-bosanski jezik i nekoliko godina radila u arhivima u Beogradu, Zagrebu i Ljubljani. Uspostavila je veze sa mnogim regionalnim institucijama i akademskom populacijom, NGO-ima i osobama koje su joj dale pouzdane informacije i dokumente.

Drugi konkretan predlog je uvođenje koncepta blizanačkih kultura, koji mi je sa svojom operativnošću već mnogo pomagao u balkanologiji u kojoj Jugoslavija ima posebno mesto, i kao kulturna invencija, i kao istorijska i politička realnost ${ }^{5}$. Upotrebljavam termin blizanačke kulture da opišem kulturne odnose i da konceptualizujem te odnose. Bliskost i intimnost blizanačkih kultura je posebno koristan okvir za istraživanje kolonijalizma u regionu i tu mislim na kulturni kolonijalizam koji je poprimio konačne oblike za vreme rata 1991-1995. u Jugoslaviji i još uvek je aktivan. Blizanačke kulture naime razvijaju posebno držanje u samoreprezentaciji prema trećem, koji je često zamišljen kao saveznik (stari, novi, istorijski, nekadašnji, izdajnički itd.) ili kao neprijatelj (sa skoro istom indeksacijom). Ponekad je nužno uputiti se u tu džunglu naracija da bi se razumelo kako mašine imaginarnog deluju, to jest kako blizanačke kulture razvijaju paralelne strategije izbiranja, markiranja i fabuliranja trećega, koji je obično politički, istorijski ili kulturni autoritet (velike sile, velike države, velike religije i sl.). Blizanačke kulture, čak i ako nemaju ništa malo u svom imaginarijumu, zadržavaju malenost u hipo-tekstu i vidno u svojoj diskurzivnoj produkciji.

Blizanačke kulture kao pojam posebno dobro odgovaraju srpsko-hrvatskom lingvističkom i kulturnom prožimanju. Nemoguće je razumeti mnoge književne fenomene ili likovnu umetnost u bilo kojoj od dve nacio-

${ }^{5}$ Twin Cultures je kao termin upotrebljen da se opišu odnosi korejske i japanske kulture: The Koreans and the Japanese - Twin Cultures: Dissimilarity in Similarity / Kankokujin to Nihonjin: sotsui bunka no purizumu, 1983. Nisam uspela naći više podataka o mogućem razvoju ovoga koncepta u drugom kontekstu. 
nalne kulture ako nisu posmatrane zajedno, kao paralele ili komparativno. Čak i u slučaju različitih jezika, recimo slovenačkog i hrvatskog, nije moguće razumeti kulturni razvoj bez paralelnog gledanja i komparativne perspektive. Isto važi za blizanačke kulture i njihove odnose između Srbije, Crne Gore i Bosne i Hercegovine: lingvističke politike teku u istome smeru kao i kulturne. Sve to ukazuje na specifične odnose kolonizatora i kolonizovanog, koji nije uvek vidljiv u imaginarijumu nostalgije. Imajući u vidu ove bliskosti kultura, koje se često razvijaju izvan državno sponzorisanih veza, nužno je razviti precizan metodološki okvir zasnovan na genološkim (povezanim sa žanrovima), rodnim, diskurzivno-strateškim i postkolonijalnim epistemologijama, i sve to na interdisciplinarnoj osnovi. Koncept blizanačkih kultura uspostavlja čitav niz novih paradigmi i pomeranja paradigmi, uključuje naracije i pomene izbačene iz nostalgičnog imaginarijuma, kao što su pacifistički aktivizam tokom rata, ženske strategije izbegavanja mobilizacije, antinacionalizam, izrugivanje patriotizma i tako dalje. Koktel nostalgije i komodifikacije često isključuje konflikt i ironiju, da i ne pominjemo kritičko mišljenje. Koncept blizanačkih kultura, unutar interdisciplinarnog pristupa prilagođenog mapi isprepletanih tematskih linija u nostalgičnim naracijama, deluje konačno kao kutija sa dekonstrukcijskim alatom. Ona bi morala davati mogućnost da se destabilizuju i ismeju letargične, imperijalne, patrijarhalne i sve druge „univerzalizirajuće” narativni ušitki ironija je tu strukturni element. Blizanačke kulture kao koncept otkrivaju procesualne aspekte nostalgičnih i para-nostalgičnih čišćenja, cenzura i akomodacija. On može pridobiti status simboličke platforme lustracije, posebno u kulturi, i funkcionisati umesto zaboravljene disidentske etike. Disidentsko pozicioniranje je nestalo iz kultura koje su nestale u Jugoslaviji, zajedno sa sistemom koji je brižno sužavao kulturu i mišljenje. Kako se disidencija neposredno pred rat raspala u dve nejednake grupe, na neverovatnu ali uspešnu mešavinu antikomunističkih i prokomunističkih nacionalista, i na drugoj strani na temeljno smanjene i oslabljene antiratne, prema ljudskim pravima usmerene grupe i pojedince, nestajanje jugoslovenske disidencije otvara ne samo specifičan istorijski, nego i epistemološki problem. Većina uticajne kulturne i akademske produkcije tokom rata koju je vredno pamtiti nastala je u okrilju ove druge grupe, manjine, koja je isto tako ključna za uspostavljanje osnovne kritičke perspektive nanovo izmišljenih nacionalnih kultura. 
Koncept blizanačkih kultura omogućuje različit pristup fenomenu nostalgije i dozvoljava objektivnije i antropološki ubedljivije objašnjenje ponašanja koje može biti odvojeno od uobičajenog eskapističkog i potrošačkog uslovljavanja potreba: one se mogu usmeravati/preusmeravati i tako zamagliti strategije koje su upisane u imaginarijum. Koncept blizanačkih kultura nužno uvodi stvarnosti svakodnevice i modele ponašanja koji ne mogu biti lako ,prevedeni” u imaginarne potrebe, već čvrsto ostaju u oblicima kohabitacije - one socijalne i antropološke odlike koju podcrtava Svetlana Boym u svom istraživanju sovjetske nostalgije (Boym 2002). U slučaju blizanačkih kultura, kohabitacija dvaju rastućih (ili opadajućih, zavisno od trenutno vladajućeg političkog diskursa) etničkih identiteta otvara veliko polje za istraživanje strategija nostalgične manipulacije.

Moguća linija istraživanja ide kroz teoriju kulturne intimnosti koju je postavio Michael Herzfeld (Herzfeld 1996; 2005). Lokacije nesigurnih narativnih oblika nacionalnog pripadanja koje se menjaju, određujući socijalno udaljene ili suprotstavljene mesto - vreme naslage (socijalne grupe, elite - obični građani, niski i visoki javni diskurs, prilikom uslovljene ili svakodnevne izjave i gestovi) uvode u još zapleteniju mrežu kada dođe do iznenadnih promena povezanih sa razdvajanjem nacionalnih identiteta i sa teškim radom na invenciji novih razlika, kao u slučaju blizanačkih kultura: srpsko-hrvatske, bosansko-srpske, bosansko-hrvatske. Model blizanačkih kultura priziva koncept strukturne nostalgije u novoj narativnoj okolini, koja se sastoji od konfliktnih linija naracije.

Prva je među tim linijama etiološka, traženje razloga i uzroka. Pitanje zašto blizanačke kulture nisu mogle zajedno živeti može uključiti evolucionističku priču - ,prirodne” uzroke, glavne istorijske preokrete na osnovu školskih udžbenika, para-antropološko stereotipiziranje. Druga linija su personalizovane priče koje oblikuju slojeve mitologije sa mnogo zajedničkih naracija, uglavnom zasnovanih na stereotipima. Ponekad su te personalizovane priče bile promovisane od strane zvaničnih tvoraca priča, medija, kao na primer priča o razvodima „mešanih parova”. Treća - postoji nezgodna jugoslovenska naracija koja lebdi između zvaničnog diskursa o nedavnoj prošlosti i onoga što je potrebno običnim ljudima (profit, mreženje, lični zahtevi). Između ove tri linije naracije postoji shizofreni diskurzivni prostor u kojem su zapletene konfliktne naracije i prakse: recimo, odbrana razloga za raspad Jugoslavije i u isto vreme profitiranje od jugoslovenske 
nostalgije. Mnoge tehnike bricolage-a učestvuju u organizovanju naracija. Jedna od zajedničkih tačaka diskurzivnog sretanja je invencija zajedničkog neprijatelja za blizanačke kulture (Romi, muslimani/katolici/pravoslavci, Jevreji, žene, gejevi/lezbejke su u uobičajenome „bazenu” izbora).

Moja argumentacija protiv izvesne lakoće pristupa problemu jugonostalgije može se delimično neutralizovati očajničkim pozivom na filološku tačnost, metodološku korektnost i poštovanje nekih tradicionalnih akademskih vrednosti. Svesna toga, bila sam još više motivisana da tražim zadovoljavajuće načine vrednovanja istorijskih, antropoloških, socijalnih i kulturnih istraživanja o jugonostalgiji, kako ne bih upala u (inače privlačnu) zamku površnih formula, jednostavnog žargona i posledičnih akademskih komoditeta. Upravo stoga uvodim metodološki nanos iz druge discipline - proveru terena (ground truthing). To donosi paket značenja, procedura i mogućnosti ponovnog premišljanja jugonostalgičnih realnosti. Provera terena je arheološki termin, recikliran i resemantiziran u novome kontekstu (Hargrave 2006: 269-304). Kao što se provera terena odnosi na proveru sakupljenih podataka (od satelita, geografskih mapa, usmene tradicije) na terenu, koju izvodi sam istraživač, tako bi se u novome kontekstu odnosila na proveru osnovnih antropoloških modela koji se mogu aplicirati na sve kulturne formacije na terenu, u njihovoj recepciji. U slučaju Jugoslavije (istorijske i izmišljene) nekoliko takvih osnovnih antropoloških modela se može postaviti kao koristan zbir alatki za interpretaciju. Među njima je svakako patrijarhat najdublje upisan, strukturno funkcionalan i diskurzivno uspešan; moguće je razumeti patrijarhat kao longue durée. U ovome specifičnome slučaju, patrijarhat se može videti kao jedini socijalno-kulturni kontinuitet od antike na Balkanu, suprotstavljen izmišljenim etničkim kontinuitetima. Opsesivni narativni obrasci „,najstarijih” na Balkanu, koji prate najuspešniji, grčki model, oblikuju drugi specifičan obrazac, neuporedivo slabiji u socijalnom i kulturnom uticaju na svakodnevni život i njegove realnosti, ali njegova prisutnost se ipak može primetiti. Drugi način istraživanja takvih naracija bio bi naći njihove tragove u medijima, štampanim i elektronskim, i u proizvodima masovne kulture. Prelaz od ratne propagande u svakodnevne diskurzivne formule bio bi vrlo izazovan za istraživanje i razumevanje u određenom dijahronijskom odlomku. Ova dva slučaja, kao rezultat provere terena „metaforizirane” u model razmišljanja 
i interdsciplinarni metod, već formiraju metodološki okvir za komparativnu analizu blizanačkih kultura.

Filološki postulat koji sam već spomenula izgleda tako neubedljivo kao deo bilo kojeg savremenog metodološkog pristupa. Ja ga razumem kao kritički glas koji ponovo poštuje neke osnovne, ali prečesto zaboravljene i izmenjene zahteve koji se tiču poštenog odnosa prema učenju i istraživanju u humanistici. Primera radi, jednostavno i sigurno ne dugotrajno proveravanje u rečnicima ne bi rezultiralo u filološki pogrešnom neologizmu titostalgija. Nema mnogo stvari koje bi se morale objašnjavati kada je reč o poštovanju filološkog rada, nema zavodljive teorije niti glatke metodologije. Ali ako je nužno podsećati na ovu vrstu dužnosti, stvari ne izgledaju previše dobro u svetu akademije i naučnog istraživanja. Površnost i plitkost su se odomaćile, što je bez sumnje posledica nužde da se proizvodi i prikazuje brzo i mnogo.

Možda ću izgledati suviše dosadna i patronizirajuća - podsećati na filologiju izvesno ima takav učinak. To je jedan od razloga što predlažem metodološki pristup koji prati simbolička značenja iz regiona. Postoji železničko i putno čvorište, Vrpolje u Hrvatskoj. Važno je još i danas, i bilo je simbolična tačka ranije, kada je označavalo zamenjivanje vozova, promenu pravca, rastajanje. Bilo je i tematsko čvorište za mnoge šale i viceve. „Ići zajedno do Vrpolja” bi dakle označavalo upotrebu zajedničkih, kooperativnih, međusobno zamenljvih metodologija do jedne tačke, a zatim razdvajanje u specifične disciplinarne puteve: putovanje zajedno do te tačke bi donelo ojačavajuće procedure dve ili više disciplina ujedinjenih u tematskoj orijentaciji. Disciplinarna grananja bi pomogla boljem definisanju istraživačkih ciljeva i pročišćavanju koncepata između istraživača, specifični epistemološki pristupi bi omogućili viši nivo istraživanja posle „Vrpolja”.

Sa tim metodološkim komentarima završavam svoju intervenciju. Po mom mišljenju, nužno je misliti bilo koji socijalni i kulturni fenomen danas u rodnom konceptualnom pejzažu. Takva korektivna strategija je posebno važna kada se imaju na umu istorijske dimenzije: istorija je disciplina u kojoj je insertiranje sitnica i fragmenata ženske ili rodno opredeljene istorije zahtevani minimum, jer mnogi argumentacijski pravci započinju od onoga što se razume kao ,istorijska činjenica”. Ako su te činjenice prihvaćene bez ikakve rodne perspektive, mogu predstavljati ogoljen falsifi- 
kat. Rodne perspektive najčešće otkrivaju cenzurisane oblike otpora. Počev od mita o Kosovu, u koji se čitav osnovni socijalni, kulturni i ritualni odgovor žena na rat - izvesno negativan - može učitati (Slapšak 2005: 95111) samo koristeći postojeće istorijske izvore, pa sve do ženskog otpora ratu i represije koja je sledila, svet žena u Jugoslaviji i posle je uvek pokazivao nedvosmislene oblike opozicije. Ova opozicija poništava svaku nostalgičnu naraciju, štaviše, čini je nemogućom otkrivajući manjak istine i poštenja. Svaka nostalgična naracija o Jugoslaviji je lažna ako ne registruje dinamično menjanje rodnog pozicioniranja, od rane jugoslovenske emancipacijske politike pa do mizogine kritike socijalizma i tranzicijske „strukturne mizoginije”. Ponovna invencija komunističke prošlosti kao isključive krivice i odgovornosti žena, koje su navodno bile naklonjenije komunizmu jer im je dao više prava, zatvara savršen cirkularni argument koji izaziva više nove mizoginije. Neophodnost da se re-emancipuje jugoslovenski feminizam prošlosti i da se tako prodrmaju još uvek fragmentirane i deprimirane studije roda u regionu izgleda neizbežna.

\section{Literatura}

Bonfiglioli Ch., 2012, Revolutionary Networks. Women's Political and Social Activism in Cold War Italy and Yugoslavia (1945-1957), PhD disertation, 14. September.

Boym S., 2002, The Future of Nostalgia, New York.

Finkielkraut A., 1992, Comment peut-on être croate?, Paris.

Funk N., Mueller M. (ur.), 1993, Gender Politics and Post-Communism: Reflections from Eastern Europe and the Former Soviet Union, London.

Handke P., 1996a, Eine winterliche Reise zu den Flüssen Donau, Save, Morawa und Drina oder Gerechtigkeit für Serbien, Frankfurt.

Handke P., 1996b, Zimsko putovanje do reka Dunava, Save, Morave i Drine ili Pravda za Srbiju, prev. Z. Krasni, Beograd.

Hargrave M., 2006, Ground Truthing the Results of Geophysical Surveys, u: J.K. Johnson, Remote Sensing in Archaeology: An Explicitly North American Perspective, University of Alabama.

Hercfeld M., 2005, Kulturna intimnost: socijalna poetika u nacionalnoj državi, Beograd.

Herzfeld M., 1996, Cultural Intimacy: Social Poetics in the Nation-State, New York. 
Salecl R., 1994, The Spoils of Freedom. Psychanalysis and Feminism After the Fall of Socialism, New York.

Slapšak S., 2005, Women's memory in the Balkans: the alternative Kosovo myth, „Anthropological journal on European cultures" br. 14, str. 95-111.

Slapšak S., 2011, Twin cultures and Rubik's cube politics: the dynamics of cultural production in pro- $Y U$, post-YU, and other $Y U$ inventions, u: Defragmenting Yugoslavia. Südosteuropa, Jg. 59, H. 3, ur. I. Ristić, Regensburg, str. 301-314.

Stiglmayer A. (ur.), 1994, Mass Rape: The War Against Women in Bosnia-Herzegovina, University of Nebraska.

Velikonja M., 2010, Titostalgija, prev. B. Dimitrijević, Beograd. 
